\begin{abstract}
Hossein Moravej ${ }^{1 \star}$, Mahmood Goodarzi $^{2}$ and Zohreh Karamizadeh ${ }^{1}$

${ }^{1}$ Pediatric Department, School of medicine, Shiraz University of Medical Sciences, Shiraz, Iran ${ }^{2}$ School of Medicine, Shiraz University of Medical Sciences, Shiraz, Iran

Dates: Received: 23 May, 2016; Accepted: 14 June, 2016; Published: 15 June, 2016

${ }^{*}$ Corresponding author: Hossein Moravej, MD, Pediatric Endocrinologist, Associated Professor, Pediatric Department, School of Medicine, Shiraz University of Medical Sciences, Shiraz, Iran, Namazi Hospital, Shiraz, Iran, Tel: 00989171058371; Fax: 00987136474298; E-mail: Drmoravej@yahoo.com www.peertechz.com
\end{abstract}

Keywords: HbA1C; Autoimmune disease; Diabetes mellitus type 1

\section{Research Article \\ The Relation between Demographic Factors, Family History, Concomitant Autoimmune Diseases and Glycemic Control in Children with Type 1 Diabetes, A Cross- Sectional Study}

\begin{abstract}
Background: Type 1 diabetes mellitus (T1DM) is a common disease which causes acute and chronic complications such as diabetic ketoacidosis, retinopathy, nephropathy, and atherosclerosis. Improvement in glycemic control can prevent these complications.

Objectives: This study aimed to assess the role of demographic factors, family history of diabetes and concomitant autoimmune diseases on glycemic control in children with T1DM in the south of Iran.

Materials and Methods: One hundred children with T1DM who were referred to a pediatric diabetes subspecialty clinic were enrolled in the study. Patients with type 2 and other types of diabetes and the ones whose diabetes type was not clinically clear were excluded from the study. After taking history and physical examination, data collection forms about the participants' demographic factors were filled out.

Hemoglobin A1C ( $\mathrm{HbA1C})$ level, total Immunoglobulin A ( $\operatorname{lgA})$, anti-tissue transglutaminase $\lg \mathrm{A}$, T4 and thyroid stimulating hormone were measured. Descriptive statistics were applied for analysis of the data.

Results: Older patients had significantly higher $\mathrm{HbA1c}$ levels $(P$-value $=0.023)$ According to linear regression model, $\mathrm{HbA} 1 \mathrm{C}$ level increases up to about $\% 12$ per year. Other factors such as sex, parental education, and family history of diabetes and concomitant autoimmune diseases (hypothyroidism and celiac disease) had no significant relationship with $\mathrm{HbA} 1 \mathrm{C}$ level.

Conclusions: As the patient grows, his/ her glycemic control worsens. Therefore, more strict efforts should be made as to education, more expert visits and more social aids in order to protect from short term and long term complications.
\end{abstract}

\section{Introduction}

T1DM is considered as a chronic common disease which involves about one in every 400 to 600 adolescents [1]. T1DM has long-term complications and it may affect the eyes, kidneys and autonomic and peripheral nervous system. However, pathophysiology of these complications is not clear. It seems that hyperglycemia plays an important role in this regard [2]. Patients with T1DM are at higher risk of developing other autoimmune diseases such as autoimmune thyroiditis and celiac disease $[3,4]$. Glycemic control improvement in a child with T1DM leads to a delay in starting and also decreasing the development of micro-vascular diabetes complications [5]. Diabetes needs a constant medical care and personal control by the patient to prevent its short-term complications and decrease the risk of long-term ones [6]. Concerning the American Diabetes Association guidelines, optimal (HbA1C) level in childhood and adolescence is below 7.5\%. Acquisition of this glycemic target in children with T1DM is a hard challenge [5]. Several studies have been conducted on the effects of different factors on controlling blood sugar level in children with T1DM in different countries and have shown different results. Although methods of controlling the blood sugar level and demographic factors are different in Iran, there is a need to investigate and analyze this issue in our country.

\section{Objective}

This study was conducted to find out the effect of several environmental factors on the control of T1DM.

\section{Materials and Methods}

This study was carried out on 100 children with T1DM who had referred to a pediatric diabetes subspecialty clinic were affiliated to Shiraz University of Medical Sciences from May 2014 to January 2015. Inclusion criteria were type I diabetes mellitus definitely diagnosed based on World Health Organization (WHO) definition [7], aged between 1 and 18 years old, and being diagnosed with disease for more than 1 year, to rule out the effect of honeymoon period. 
After taking informed consent from the parents, for each patient, data collection form which included demographic information (date of birth, sex, residency, and parents' education), age and time of diagnosing diabetes, the way the disease appeared (with or without diabetic ketoacidosis), related diseases, and family history of any type of diabetes was completed. Then, at follow up, levels of HbA1C, total Immunoglobulin a (IgA), anti-tissue transglutaminase $\operatorname{IgA}, \mathrm{T} 4$, and Thyroid Stimulating Hormone (TSH) of all patients were checked and their levels were recorded. SPSS version 18 was used for data analysis. One-way ANOVA was applied for comparing the parents' education, family history, and related diseases. Independent T-test was used to find the differences in sex and Pearson correlation for age. For all analyses, $P$ value of $<0.05$ was considered as statistical significance.

This study was approved by Ethical Committee of Shiraz University of Medical Sciences.

\section{Results}

Totally, the questionnaires were filled out for 100 ( 48 boys, and 52 girls) children with T1DM with the mentioned criteria. The patients' ages range was $4-18$ years with amean of $10.67 \pm 3.85$ years. The majority of patients were 7 to 12 years old (\%57). In terms of father's education, $66 \%$ of the fathers had high school diploma or below diploma. Only $3 \%$ of them were illiterate and others had university degrees. Regarding mother's education, 78\% had high school diploma or below diploma, and just $2 \%$ were illiterate, and the rest had university degrees. $55 \%$ of the patients has positive family history of diabetes (type I and II), of 10\% were related to first-degree relatives, $40 \%$ to second-degree relatives and 5\% to third-degree relatives. $85 \%$ of the patients had no concomitant diseases other than diabetes. On the other hand, $2 \%$ had hypothyroidism, $2 \%$ had celiac disease, and $11 \%$ had other diseases such as iron deficiency anemia and glucose 6 phosphate dehydrogenase deficiency.

As seen in Table 1, HbA1C level increased significantly with advancing aging ( $\mathrm{p}$-value $=0.023$ ). According to linear regression model, HbA1C level increased up to $0.117 \%$ per year. Certainly, this relationship is weak because of the irrelevancy of some data.

Table 2 shows that $\mathrm{HbA1C}$ mean is higher among girls, but this difference is not significant statistically.

As seen in Tables 3-6, there was no significant relationship between the parents' education, concomitant diseases (hypothyroidism and celiac disease) and family history of diabetes with HbA1C level.

Table 1: Correlation between age and $\mathrm{HbA} 1 \mathrm{c}$ among patients with Type 1 diabetes mellitus.

\begin{tabular}{|llll|} 
& & HbA1c (\%) & age \\
& Pearson Correlation & 1 & 0.227 \\
HbA1c $(\%)$ & P value & & 0.023 \\
& Number & 100 & 100 \\
\hline
\end{tabular}

Table 2: Correlation between sex and $\mathrm{HbA} 1 \mathrm{c}$ among patients with Type 1 diabetes mellitus

\begin{tabular}{|l|l|l|l|}
\hline Sex & Number & Mean HbA1C & p-value \\
\hline Male & 48 & $8.31 \pm 2.00$ & \\
\hline Female & 52 & $8.42 \pm 1.98$ & 0.78 \\
\hline
\end{tabular}

Table 3: Correlation between father's education and $\mathrm{HbA} 1 \mathrm{c}$ among patients with Type 1 diabetes mellitus.

\begin{tabular}{|l|l|l|l|}
\hline Father education & Number & Mean HbA1C & p-value \\
\hline Illiterate & 3 & $8.43 \pm 1.44$ & \\
\hline Primary school to high school diploma & 38 & $8.41 \pm 2.35$ & \\
\hline High school diploma & 28 & $8.55 \pm 1.66$ & \\
\hline Associate degree & 6 & $8.16 \pm 2.49$ & \multirow{2}{*}{0.95} \\
\hline Bachelor degree and upper & 25 & $8.14 \pm 1.71$ & \\
\hline
\end{tabular}

Table 4: Correlation between mother's education and $\mathrm{HbA} 1 \mathrm{c}$ among patients with Type 1 diabetes mellitus.

\begin{tabular}{|l|l|l|l|}
\hline Mother education & Number & Mean HbA1C & p-value \\
\hline Illiterate & 2 & $9.7 \pm 0.14$ & \\
\hline Primary school to high school diploma & 44 & $8.45 \pm 2.33$ & \\
\hline High school diploma & 34 & $8.39 \pm 1.56$ & \\
\hline Associate degree & 6 & $6.93 \pm 1.01$ & \multirow{2}{*}{0.38} \\
\hline Bachelor degree and upper & 14 & $8.46 \pm 2.00$ & \\
\hline
\end{tabular}

Table 5: Correlation between family history and $\mathrm{HbA} 1 \mathrm{c}$ among patients with Type 1 diabetes mellitus.

\begin{tabular}{|l|l|l|l|}
\hline Family history & Number & Mean HbA1C & p-value \\
\hline First-degree relative & 10 & $7.96 \pm 1.95$ & \\
\hline Second-degree relative & 40 & $8.38 \pm 1.81$ & \\
\hline Third-degree relative & 5 & $7.64 \pm 0.58$ & \multirow{2}{*}{0.72} \\
\hline Without family history & 45 & $8.52 \pm 2.23$ & \\
\hline
\end{tabular}

Table 6: Correlation between associated diseases and $\mathrm{HbA} 1 \mathrm{c}$ among patients with Type 1 diabetes mellitus.

\begin{tabular}{|l|l|l|l|}
\hline Related diseases & Number & Mean HbA1C & p-value \\
\hline Hypothyroidism & 2 & $9.35 \pm 0.35$ & \\
\hline Celiac disease & 2 & $7.70 \pm 0.14$ & \multirow{2}{*}{0.85} \\
\hline Other diseases & 11 & $8.20 \pm 2.02$ & \\
\hline Without any diseases except T1DM & 85 & $8.38 \pm 1.98$ & \\
\hline
\end{tabular}

In children with T1DM, who had hypothyroidism, mean HbA1C was $9.35 \pm 0.35$ that is significant clinically but non-significant statistically as compared to other diabetic children.

\section{Discussion}

In this study, the only effective factor on glycemic control and HbA1C level was the patients' ages, so that older ones had higher $\mathrm{HbA1C}$ and poorer glycemic control. Several studies have revealed this issue. According to similar studies done in Japan [8], United States of America [9] and Scotland [10], HbA1C was significantly higher in adolescents than younger children. It may occurs due to psychosocial problems such as independence from the family, decreasing physical activities, hormonal changes like high resistance to insulin during puberty [11] and to some extent due to progressive nature of the disease.

Based on this study, sex had no effect on glycemic control. Similar studies carried out in Egypt [5] and Japan [8], confirmed that issue. pathophysiologically, sex is not a risk factor for poor glycemic control. But a few studies revealed that the mean of $\mathrm{HbA1C}$ in girls was significantly higher than boys [12].

Positive family history had no impact on glycemic control in our study. Also, the study done in Egypt [5], confirmed that point. However, another study in Italy indicated that $\mathrm{HbA} 1 \mathrm{C}$ was lower in 
children whose first-degree and second-degree relatives had diabetes [13]. This difference between patients of our country and Italy may show that our patients have not enough information about their diseases; therefore, they cannot share their knowledge and attitude with other relatives suffering from diabetes.

In fact, due to frequent history of diabetes among families, education regarding their diseases improves the outcome of other related patients.

According to this study there was no significant relationship between the parents' education and glycemic control in children with T1DM. Another study in Saudi Arabia indicated that mothers with higher education had diabetic children with better glycemic control [14]. In addition, another study in Portugal showed a significant relationship between low education of parents and poor glycemic control [15]. Highly educated parents can be more oriented to the symptoms and complications of T1DM compared to less educated parents and it can be effective for better control of the disease. However, in our country highly educated parents are usually busy and they may have less time to take care of their diabetic children leading to lack of control of T1DM. It seems that in our region, these effects cause education as a non-effective factor for blood sugar control.

Only 2 out of 100 patients in our study had hypothyroidism. Mean $\mathrm{HbAlc}$ in these hypothyroid patients was higher than other patients but this difference was not significant. Of course, this low number of cases makes the statistical analysis unreliable. Based on a study done on 330 children with T1DM in 2015, autoimmune thyroid disease causes poorer glycemic control [16]. Moreover, according to a systematic review conducted on the relationship between autoimmune thyroiditis and T1DM in 2013, there was a relationship between non-treated hypothyroidism and poor control of blood sugar in patients with T1DM. But in another study done on 148 patients with T1DM in 2009, no difference was found in blood sugar control among patients with autoimmune thyroiditis and those without it $[17,18]$.

Therefore, the effect of thyroid disease on glycemic control in patients with T1DM is not clear and it requires more studies to be confirmed.

In this study, there was no significant relationship between celiac disease and HbA1C in children with T1DM. Another study carried out on children with T1DM in 2012 showed that there was no difference between patients who have diabetes as well as celiac disease and the ones who had no celiac disease regarding glycemic control [19]. This issue was also confirmed in the systemic review done on the relationship between celiac disease and T1DM in 2015 [20].

\section{Conclusion}

Blood sugar control in patients with T1DM will worsen the patient ages. Therefore, with advancing age, patients need more education and medical and psychosocial aids.

However, blood sugar control is not related to sex, family history of diabetes, and parents' education.

\section{Limitations}

The number of participants was limited. Therefore, more studies with higher number of participants are needed to determine the effective factors on glycemic control among patients with type 1 diabetes.

\section{Acknowledgment}

This study was supported by Shiraz University of Medical Sciences and approved with code No: 90-01-01-6907. The study was extracted from the thesis written by Mohmood Gudarzi for M.D. degree.

The authors would like to thank the center for development of clinical research of Nemazee Hospital in Shiraz University of Medical Sciences, Shiraz, Iran and also Dr. Nasrin Shokrpour for editorial assistance.

\section{Author Contributions}

Concept and design: Hossein Moravej, Mahmmod goodarzi. Acquisition of data: Hossein Moravej, Mahmmod goodarzi. Analysis and interpretation of data: Hossein Moravej, Zohreh Karamizadeh. Critical revision of the manuscript for important intellectual: content: Hossein Moravej, Zohreh Karamizadeh.

\section{References}

1. McNally K, Rohan J, Pendley JS, Delamater A, Drotar D (2010) Executive functioning, treatment adherence, and glycemic control in children with type 1 diabetes. Diabetes Care 33: 1159-1162.

2. Nathan DM, Cleary PA, Backlund JY, Genuth SM, Lachine JM, et al. (2005) Intensive diabetes treatment and cardiovascular disease in patients with type 1 diabetes. N Engl J Med 353: 2643-2653.

3. Barker JM, Yu J, Yu L, Wang J, Miao D, et al. (2005) Autoantibody "subspecificity" in type 1 diabetes: risk for organ-specific autoimmunity clusters in distinct groups. Diabetes Care 28: 850-855.

4. Hummel S, Hummel M, Banholzer J, Hanak D, Mollenhauer U, et al. (2007) Development of autoimmunity to transglutaminase $\mathrm{C}$ in children of patients with type 1 diabetes: relationship to islet autoantibodies and infant feeding. Diabetologia 50: 390-394.

5. Mohammad HA, Farghaly HS, Metwalley KA, Monazea EM, Abd El-Hafeez HA (2012) Predictors of glycemic control in children with Type 1 diabetes mellitus in Assiut-Egypt. Indian J Endocrinol Metab 16: 796-802.

6. Menzin J, Korn JR, Cohen J, Lobo F, Zhang B, et al. (2010) Relationship between glycemic control and diabetes-related hospital costs in patients with type 1 or type 2 diabetes mellitus. J Manag Care Pharm 16: 264-275.

7. Silverstein J, Klingensmith G, Copeland K, Plotnick L, Kaufman F, et al (2005) Care of children and adolescents with type 1 diabetes: a statement of the American Diabetes Association. Diabetes Care 28: 186-212.

8. Urakami T, Suzuki J, Yoshida A, Saito H, Ishige M, et al. (2010) Association between Sex, Age, Insulin Regimens and Glycemic Control in Children and Adolescents with Type 1 Diabetes. Clin Pediatr Endocrinol 19: 1-6.

9. Urbach SL, LaFranchi S, Lambert L, Lapidus JA, Daneman D, et al. (2005) Predictors of glucose control in children and adolescents with type 1 diabetes mellitus. Pediatr Diabetes 6: 69-74.

10. Scottish Study Group for the Care of the Young Diabetic (2001) Factors influencing glycemic control in young people with type 1 diabetes in Scotland: a population-based study (DIABAUD2). Diabetes Care 24: 239-244.

11. Chowdhury S (2015) Puberty and type 1 diabetes. Indian J Endocrinol Metab 19: S51-54. 
12. Setoodeh A, Mostafavi F, Rabbani A, Hedayat T (2011) Female sex as a risk factor for glycemic control and complications in Iranian patients with type one diabetes mellitus. Iran J Pediatr 21: 373-378.

13. Bizzarri C, Paladini A, Benevento D, Fierabracci A, Cappa M (2015) Family history and ethnicity influencing clinical presentation of type 1 diabetes in childhood. J Endocrinol Invest 38: 1141-1143.

14. Al-Odayani AN, Alsharqi OZ, Ahmad AM, Khalaf Ahmad AM, Al-Borie HM, et al. (2013) Children's glycemic control: mother's knowledge and socioeconomic status. Glob J Health Sci 5: 214-226.

15. Marques Rde M, Fornés NS, Stringhini ML (2011) Socioeconomic, demographic, nutritional, and physical activity factors in the glycemic control of adolescents with type 1 diabetes mellitus. Arq Bras Endocrinol Metabol 55: 194-202.
16. Korzeniowska K, Ramotowska A, Szypowska A, Szadkowska A, Fendler W, et al. (2015) Family history and ethnicity influencing clinical presentation of type 1 diabetes in childhood. J Pediatr Endocrinol Metab 28: 275-278.

17. Shun CB, Donaghue KC, Phelan H, Twigg SM, Craig ME (2014) Thyroid autoimmunity in Type 1 diabetes: systematic review and meta-analysis. Diabet Med 31: 126-135.

18. Severinski S, Banac S, Severinski NS, Ahel V, Cvijovic K. (2009) Epidemiology and clinical characteristics of thyroid dysfunction in children and adolescents with type 1 diabetes. Coll Antropol 33: 273-279.

19. Taler I, Phillip M, Lebenthal Y, de Vries L, Shamir R, et al. (2012) Growth and metabolic control in patients with type 1 diabetes and celiac disease: a longitudinal observational case-control study. Pediatr Diabetes 13: 597-606.

20. Akirov A, Pinhas-Hamiel O (2015) Co-occurrence of type 1 diabetes mellitus and celiac disease. World J Diabetes 6: 707-714.

Copyright: (c) 2016 Moravej $\mathrm{H}$, et al. This is an open-access article distributed under the terms of the Creative Commons Attribution License, which permits unrestricted use, distribution, and reproduction in any medium, provided the original author and source are credited. 